\title{
3. A vida associativa e o Secretariado Geral da AULP (2006-2010; 2014-2016)
}

\author{
Cristina Montalvão Sarmento
}

Secretária-Geral da AULP (2006-2010 / 2014-2016)

Cultura e poder são forças interligadas que se podem utilizar como um instrumento em benefício estrutural. Importa assegurar que as comunidades de língua portuguesa o saibam conservar, potenciar e transmitir. A língua enquanto código de cultura partilhado é fonte de poder. Este tipo de poder está presente na dimensão política e económica, e mostra que o tipo de poder que a "cultura" veicula tem certamente graus de imaterialidade mas dá corpo a tipos de exercício do poder em formatos benévolos que nos comprazemos a preferir em sociedades pacificamente organizadas. Estes auspícios terão presidido à fundação da Associação das Universidades de Língua Portuguesa pelos intelectuais que pressentiram e intuíram o valor potencial da língua partilhada.

Desde então as noções convencionais de cultura esvaziaram-se e o papel da cultura expandiu-se como nunca para as esferas política e económica. Se tomarmos aqui como pressuposto que a cultura não precisa de ser apreendida como a consideração particular de certos atributos (normas, valores, costumes ou crenças) que seriam as características de um qualquer grupo particular da sociedade, ou seja como a sua intrínseca identidade, a cultura pode ser considerada como um sistema simbólico que permite que as pessoas partilhem significados, e por consequência assumirmos que as transformações sociais e políticas estejam culturalmente ancoradas.

A cultura, como recurso político e económico, ganhou legitimidade e é hoje o eixo de uma nova estrutura assolada por uma racionalidade económica de tal forma que a conservação, o acesso, a distribuição e o investimento em «cultura» e nos seus resultados, se tornam prioritários e politicamente relevantes.

A alta cultura tornou-se um recurso para o desenvolvimento urbano. As indústrias da cultura de massas, em especial as indústrias do entretenimento que integram a música, o filme, o vídeo, a televisão e as revistas, a difusão por satélite e por cabo, constituem importantes contributos para os produtos internos brutos. Vendendo cidades, regiões ou inventada na tradição, a cultura como ideia e conceito, ganha novos contornos analíticos. No quadro diferenciado e dinâmico que se estabelece e vai emergindo, a AULP prosseguiu a sua atuação. 
Se a segunda metade do ano de 2006 foi o ano da estabilização do Secretariado ${ }^{1}$, por proposta da recém reassumida Presidência da Universidade do Algarve aprovada na Assembleia-geral de Macau; Já em 2007 a AULP acorrerá a Cabo Verde, onde realiza o seu XVII Encontro, para acolher no seu seio, a recém criada Universidade Estatal, sob os auspícios da «Universidade em Rede», única formulação que parece corresponder aos novos tempos e define também uma instituição criada a partir de uma rede poli mórfica anterior de Institutos de Ensino Superior acolhidos sob uma mesma autoridade académica. Assumida a necessidade científica de ser a Universidade anfitriã a propor o tema sob o qual se reúnem as Universidades e Instituições de Ensino Superior e Investigação Científica de Língua Portuguesa, será à luz deste principio de democraticidade que doravante se pugnará a atuação da AULP.

A interrupção da publicação das atas dos Encontros Científicos da AULP desde 2004, concentrará, na fase inicial, os esforços do Secretariado em disponibilizar os materiais que entretanto dispunha ou recolhe: XIV Encontro em S. Paulo, Brasil, (2004); XV Encontro em Lisboa, Portugal (2005); XVI Encontro, Macau, China (2006) e já sob o título de Universidade em Rede, XVII Encontro da Cidade da Praia em Cabo Verde, todos vindos a público entre Novembro de 2007 e Fevereiro de 2008, num esforço de recuperação que estabilizou estas edições e garantiu o acesso da comunidade aos debates neles realizados.

Estreia-se ainda o interesse em disponibilizar edições úteis e capazes de homenagear as Universidades anfitriãs dos Encontros Científicos da AULP, os que nelas se dedicam à investigação, ou se lhes devotaram ou neles se investiram de corpo e alma de investigadores e humanistas.

Assim em Cabo Verde, a reedição de «Santiago, a Ilha e os Homens» de Ilídio do Amaral; Assim, em Brasília, a colaboração com a Universidade Católica Portuguesa permitiu levar ao XVIII Encontro, em 2008, Ano Vieirino, novas fixações de textos, belamente ilustrados, de três Sermões do Padre António Vieira, Embaixador das relações luso-brasileiras. Assim, em Angola, no ano de 2009, no XIX Encontro em Luanda, foi possível renovar o acesso ao público académico, às obras de José Redinha, Etnias e Culturas de Angola e de José Grandvaux Barbosa, Carta Fitogeográfica de Angola, ambas desaparecidas, reedições agora realizadas pela AULP, fruto do empenho conjunto de várias instituições académicas. Doravante, as obras comemorativas serão parte integrante de todos os Encontros.

Entre 2006 e 2008, a atualização do logótipo, marca da Associação que regista os vinte anos, entretanto decorridos, a atualização de recursos pelo reinvestimento

\footnotetext{
1. A opção será a de nomeação de uma académica sem exclusividade de funções. Será contratado um jovem cabo-verdiano, como secretário executivo, o Mestre Suzano Costa, a par da saída por reforma de Analídia Perdigão e da indisponibilidade entretanto manifestada de Gabriel Feio, que exercia as funções de secretário-geral interino desde a saída de Dr. Alarcão Troni.
} 
na página eletrónica da AULP, para que a Universidade de Macau concorrera, conseguida a estabilidade financeira e a dignificação externa do edifico da sede, estavam criadas as condições de continuidade saudável da vida institucional da AULP.

A partir da reunião do Conselho de Ministros da CPLP realizada em Bissau, a AULP adquirirá em 2007, formalmente o Estatuto de Observador Consultivo da Comunidade dos Países de Língua Portuguesa, com o direito a assistir às reuniões de carácter técnico que se afigurem de interesse para os objetivos da AULP, onde, no entanto, funções formalizadas se cruzam com as burocracias institucionais.

Em 2008, a necessidade do adiamento de Maio para Setembro, da realização do XVIII Encontro em Brasília, consequência de dificuldades internas vividas pela Universidade Anfitriã, embaraçou a operacionalidade dos meios do Secretariado, porquanto obrigou à duplicação de meios postos à disposição da organização. No entanto, no mesmo período foram abertas as relações exteriores da AULP, nomeadamente com a União Latina e com a AUF (Associação das Universidades Francesas) e acentuou-se o esforço para reconstituir um Conselho editorial que permitisse dar continuidade à Revista Internacional de Língua Portuguesa (RILP). Em Maio de 2008, a RILP, órgão da Associação das Universidades de Língua Portuguesa, inicia a sua III $^{\mathrm{a}}$ série com uma alteração no rumo editorial da Revista. O carácter genérico das séries anteriores é abandonado em benefício da procura de temas que suscitem o interesse da comunidade universitária.

Não se tratará mais de uma revista sobre a língua portuguesa, mas em língua portuguesa, em que os diferentes estágios da ciência e os desenvolvimentos científicos dos países das comunidades que por ela e através dela comunicam, possam interagir em vários domínios científicos.

A normalização física da sede, devida ao permanente esforço de Macau, em que se tinha destacado o apoio do General Rocha Vieira, último governador do território ainda sob administração portuguesa, a reposição da capacidade editorial, a exposição pública da AULP e a sua reabilitação económica capacitaram a Associação das Universidades de Língua portuguesa para um papel reestruturado no seio do Ensino Superior dos Países de Língua Portuguesa.

No entanto, em 2009 o Encontro realizado em Luanda, Angola, é confrontado com alguns problemas logísticos face à dimensão que os Encontros anuais já tinham assumido. Não obstante o bom decurso dos trabalhos e o empenho das Universidades de acolhimento que criaram um consórcio em Luanda para acolher o Encontro, estas dificuldades a par do prolongamento das Vice-Presidência de Portugal, que se vinha demorando e por vezes conflituante com as posições firmes e atuantes da Presidência entretanto eleita, da UFMG, do Brasil, cuja determinação presidiu ao programa científico de intercâmbio institucional - PIAPPE (Programa Internacional de Apoio à Pesquisa e ao Ensino por meio 
da Mobilidade Docente e Discente Internacional), foram temas, que em conjunto, criariam desencontros vários na vida associativa.

Simultaneamente a AULP foi sendo arrastada pela abertura e atuação política e diplomática errática da CPLP em que o alargamento da posição de observador consultivo a inúmeros organismos de várias tipologias e origens, desvirtuava os projetos implementados em modelo coletivo e no âmbito do Ensino Superior, servindo simultaneamente como fonte de legitimidade de processos com visibilidade política sem real fundamento científico.

Acresce que o modelo de sucesso que a AULP representa, leva à dinamização de Associações várias concorrentes que criam competitividade interessada ao abrigo de interesses particulares, seja o GCUB (Grupo Coimbra das Universidades Brasileiras) fundamentado em razões históricas e fundado em Brasília no ano em que a AULP aí reúne, seja a Rede sul-sul que a UNILAB (Universidade da integração internacional da Lusofonia Afro Brasileira), esta última potenciada pelo interesse geoestratégico das relações SUL-SUL que as Presidências políticas do Brasil incentivaram ou ainda pequenas redes como a FORGES (Fórum da Gestão do Ensino Superior nos Países e Regiões de Língua Portuguesa), iniciativa privada, que vem utilizando o modelo AULP reunindo agrupando responsáveis, incluindo gestores e técnicos, das Instituições de Ensino Superior, com associados individuais.

O cúmulo dos factos expressos, provocariam a demissão do Secretário-Geral na Assembleia-Geral que se realizou em Macau em 2010, tendo, no entanto, ficado em preparação o Encontro a realizar em Bragança no Instituto Politécnico no ano de 2011, o que visava superar em definitivo o ultrapassado desencontro de posições entre o CRUP (Conselho de Reitores das Universidades Portuguesas) e o CCISP (Conselho Coordenador dos Institutos Superiores Politécnicos) no espaço do ensino superior português, a que não é alheia aquela demissão. A nomeação de recurso de uma secretaria executiva ${ }^{2}$, jornalista profissional, repartindo tarefas, nessa qualidade e na qualidade de secretariado para os meios de comunicação do CRUP, não foi um elemento de distensão institucional.

No entanto, a relação com os meios de comunicação social foi potenciada e alargada, ganhando visibilidade comunicacional a Associação, escolha de rumo não consensual no seio do seu Conselho de Administração, habilmente gerido pela renovada presidência moçambicana da Universidade do Lúrio, que como antes fora a da Universidade de Eduardo Mondlane, foi um elemento pacificador e manteve em rigorosa atividade a vida associativa tendo organizado um Encon-

2. Mestre Teresa Botelheiro exerce atualmente funções enquanto jornalista da RTP (desde 01/1997), formadora da World Academy (desde 01/2016) e colaboradora no Gabinete de comunicação da Agência Nacional Erasmus+ Educação e Formação. Foi assessora de comunicação do CRUP (03/2011 - 02/2014) e assessora de imprensa do Ministério da Educação e Ciência (01/2015 - 10/2015). Mestre em Marketing Estratégico pelo Instituto Superior de Comunicação Empresarial. 
tro bem sucedido em Maputo, Moçambique no ano de 2012. E, promovendo, em estreita relação com a vice-presidência Brasileira o Encontro em 2013 em Minas Gerais na Universidade Federal, Brasil.

Na transição, e com vista à estabilização da sede e da vida associativa decide o Conselho de Administração, pela mão do Presidente, Reitor da Universidade do Lúrio e da Vice-presidência de Macau, RAEM, pelo seu Vice-Reitor, a reassunção do cargo de Secretário-Geral anterior e reentrada para resolução dos conflitos laborais que, entretanto, se tinham agravado.

Retomada a normalidade das funções da sede, o retorno a Cabo Verde, pelo acolhimento da Universidade de Cabo Verde, já em franca expansão, desta vez na histórica Cidade Velha, permitiu criar no ano de 2014, a oportunidade de homenagear o último Governador de Macau, China, General Vasco Rocha Vieira, inelutável suporte da vida da Associação. A atual presidência em curso, da Universidade de Macau, agora da Região Administrativa Especial da China, representa o culminar da abertura ao espaço linguístico global, e a uma vice-presidência que prosseguiu durante mais de 28 anos, acompanhando, conhecendo e acolhendo a AULP.

De justiça importa ainda referir o significativo apoio da Fundação Macau, que se em 2006 permitiu a recuperação da sede e a estabilidade financeira, neste ano de 2016, mais uma vez permitiu o financiamento sustentável de várias atividades da sede e para a qual se regista o nosso agradecimento público.

Neste ano de 2016, em que a AULP completa trinta anos, compraz poder afirmar que a vida associativa da sede e os contextos vários que vai enfrentado positivos e negativos, não obstam ao seu progresso, confirmação de que faz prova a deslocação ao sudeste asiático e a a realização com sucesso, do seu XXVI Encontro com o acolhimento da Universidade Nacional de Timor Lorosa'e, em Timor-Leste, no mais jovem Estado que adotou como língua oficial, o português. 